\title{
VARIAÇÃO DA TEMPERATURA DA SUPERFÍCIE ATRAVÉS DE IMAGENS ASTER EM ZONAS CLIMÁTICAS LOCAIS DA CIDADE DE CUIABÁ, BRASIL
}

\author{
FERREIRA, Hugo Vilela Lemos - hugovilelalemos@usp.br \\ Universidade de São Paulo / USP \\ UGEDA JÚNIOR, José Carlos - ugeda@ufmt.br \\ Universidade Federal de Mato Grosso / UFMT
}

\begin{abstract}
RESUMO: As Zonas Climáticas Locais $(Z C L)$ em uma cidade representam padrões espaciais de elementos da superfície capazes de provocar efeitos no clima urbano. Além da morfologia, os elementos do espaço podem ser analisados por sua temperatura da superfície (Ts), através de produtos de sensoriamento remoto termal satelital, como o AST08, do sensor ASTER. Esta Ts pode ser analisada a partir de ZCLs, revelando variações espaciais e temporais. Este artigo teve como objetivo analisar a variabilidade espacial e temporal da Ts de imagens ASTER considerando como unidades espaciais ZCLs da cidade de Cuiabá, Brasil. Foram mapeadas as ZCLs de Cuiabá; obteve-se imagens ASTER de diferentes datas e horários; e comparou-se as ZCLs com a Ts de diferentes condições temporais, sazonais e horárias. Verificou-se variações na Ts em diferentes horas do dia e sazonalmente, em diferentes tipos ZCLs intraurbanas. Durante o dia, na estação seca, a Ts de ZCLs edificadas e vegetadas se assemelharam. Na estação chuvosa, as áreas edificadas se mostram mais aquecidas. Durante a noite, ZCLs edificadas apresentaram maior Ts do que vegetadas, ainda variando entre si conforme diferentes condições de adensamento e altura das edificações.
\end{abstract}

PALAVRAS-CHAVE: Cuiabá; clima urbano; temperatura da superfície; ASTER; Zona Climática Local.

SURFACE TEMPERATURE VARIATION THROUGH ASTER IMAGES IN LOCAL CLIMATE ZONES OF THE CITY OF CUIABÁ, IN BRAZIL

ABSTRACT: The Local Climate Zones (LCZ) in a city represent spatial patterns of surface elements capable of causing effects on the urban climate. In addition to morphology, space elements can be analyzed by their surface temperature (Ts) through satellite thermal remote sensing products such as AST08 from the ASTER sensor. This Ts can be analyzed from LCZs, revealing spatial and temporal variations. This article aimed to analyze the spatial and temporal variability of the Ts of ASTER images considering LCZs as spatial units in the city of Cuiabá, Brazil. Cuiabá LCZs were mapped; ASTER images of different dates and times were obtained; the LCZs were compared with the Ts from different temporal, seasonal and hourly conditions. There were variations in the Ts at different hours of the day and seasonally, in different types of intra-urban LCZs. During the day, in the dry season, the Ts of built and vegetated ZCLs are similar. In the rainy season, the built-up areas are more heated. During the night, built-up LCZs showed higher Ts than vegetated ones, still varying between different conditions of density and height of buildings.

KEYWORDS: Cuiabá; urban climate; surface temperature; ASTER; Local Climate Zone.

VARIACIÓN DE TEMPERATURA SUPERFICIAL EN IMÁGENES DE ASTER EN ZONAS CLIMÁTICAS LOCALES DE LA CIUDAD DE CUIABÁ, BRASIL

RESUMEN: Las Zonas Climáticas Locales ( $Z C L)$ en una ciudad representan patrones espaciales de elementos superficiales capaces de causar efectos en el clima urbano. Además de la morfología, los elementos del espacio pueden analizarse por su temperatura superficial (Ts), utilizando productos de teledetección térmica por satélite, como AST08, del sensor ASTER. Este Ts puede analizarse a partir de ZCLs, revelando variaciones espaciales y temporales. Este artículo tuvo como objetivo analizar la 
variabilidad espacial y temporal de Ts de imágenes ASTER considerando los ZCL como unidades espaciales en la ciudad de Cuiabá, Brasil. Las ZCLs de Cuiabá fueron mapeadas; se obtuvieron imágenes ASTER de diferentes fechas y horas; las ZCL se compararon con la Ts de diferentes condiciones temporales, estacionales y horarias. Hubo variaciones en la Ts en diferentes momentos del día y estacionalmente, en diferentes tipos de ZCL intraurbanas. Durante el día, en la estación seca, la Ts de las ZCL construidas y vegetadas son similares. En la temporada de lluvias, las zonas urbanizadas se calientan más. Durante la noche, ZCLs construidas mostraron Ts más altas que las vegetadas, aún variando según las diferentes condiciones de densidad y altura de los edificios.

PALABRAS CLAVE: Cuiabá; clima urbano; temperatura de la superficie; ASTER; Zona Climática Local.

\section{INTRODUÇÃO}

A complexidade das áreas urbanas tem como elos individuais suas diversas formas, dadas pelas condições físicas dos elementos da superfície reconhecíveis na paisagem das cidades (OKE et al., 2017; STEWART, 2011). Os tipos de assentamentos urbanos são comparáveis por características arquitetônicas das edificações, de conjuntos de lotes, padrões de cânions, quarteirões, bairros, e até mesmo elementos não artificiais que existem nas cidades, condições de solo, vegetação, hidrografia, compõem padrões tipológicos e morfológicos comparáveis. A classificação de tipos de superfícies em Zonas Climáticas Locais (ZCL; Local Climate Zones; LCZ; STEWART, 2011; STEWART \& OKE, 2012) estabelece uma metodologia de organizar dentro de um sistema de classes, as diferentes condições físicas dos elementos do espaço urbano. Agrupam características de edificações, vegetação urbana, que possuem potencialidade em promover alterações climáticas no interior da cidade. Formam ZCLs regiões de uniforme cobertura da superfície, estrutura, materialidade e atividade humana, que abrangem centenas de metros a alguns quilômetros em escala horizontal (STEWART \& OKE, 2012), na escala morfológica de bairros (OKE et al., 2017).

As ZCLs permitem uma melhoria no detalhamento do espaço analisado em estudos de climatologia urbana, na escala intraurbana, para além da noção urbano-rural. Dispostas em dois grupos, de tipos construídos ou edificados, listadas por classes numeradas de 1 a 10, e de tipos de cobertura da superfície, listadas por letras de 'A' à 'G', estão divididas as 17 classes padrão de ZCLs, propostas originalmente por Stewart (2011). "Cada ZCL é nomeada e ordenada individualmente por uma (ou mais) propriedade da superfície diferenciadora, que na maioria dos casos é a altura/densidade de objetos de rugosidade ou a cobertura da superfície dominante" (STEWART \& OKE, 2012, p. 1887, tradução nossa). Destaca-se o reconhecimento de ZCLs em razão da diferenciação de áreas intraurbanas no espaço urbano, que podem formar espaços físicos relativamente homogêneos, capazes de promover efeitos atmosféricos no clima urbano.

Estes efeitos no clima urbano provocados pelos distintos arranjos espaciais são passíveis de serem compreendidos em função da análise de propriedades físicas da superfície. Dentre estas propriedades da superfície, sua temperatura revela-se como uma importante variável para a compreensão de processos atmosféricos que ocorrem no interior dos climas urbanos, como ilhas de calor, geração de correntes de vento ou concentração de poluição 
atmosférica (OKE et al., 2017). Através de produtos de sensoriamento remoto termal satelital, como o do tipo AST08 (Surface kinetic temperature; ABRAMS et al., 2002; EOSDIS/NASA, 2001), derivado do sensor ASTER (Advanced Spaceborne Thermal Emission and Reflection Radiometer), é possível analisar a variabilidade da temperatura da superfície (Ts; Land Surface Temperature; LST) na escala intraurbana, e em diferentes instantes horários.

O produto AST08 é estimado a partir de cinco bandas infravermelhas termais do sensor ASTER, da emissividade do produto AST05 (Surface Emissivity), entre outros parâmetros (EOSDIS/NASA, 2001). O sensor ASTER, que se encontra a bordo do satélite Terra, imageia a superfície terrestre através de suas bandas termais numa resolução espacial de 90 metros, tanto no período da manhã ( 10:30h do Tempo Local) quanto a noite ( 22:30h). Suas cenas contam com uma dimensão de $60 \times 60 \mathrm{~km}$, e possuem um tempo de revisita de 16 dias. O detalhe de informações sobre a Ts nestas escalas, espacial e temporal, possibilita detectar variabilidades na superfície em análises da condição urbana, e de sua relação com efeitos do clima urbano. Isto, da mesma forma que, a classificação de ZCLs reconhece em suas unidades espaciais de análise da superfície, relações entre a morfologia e efeitos do clima urbano (STEWART, 2011; STEWART \& OKE, 2012; STEWART et al., 2014).

A disponibilidade de imagens noturnas do sensor ASTER permite um ganho qualitativo e quantitativo na análise da Ts urbana. Estudos como os de Geletič et al. (2016), Wang et al. (2018) e Zhao (2018), em áreas urbanas, utilizaram-se do esquema de ZCLs na investigação de condições da Ts através de produtos ASTER e Landsat. Eles verificaram que as ZCLs se relacionam espacialmente com a variação da Ts urbana: áreas identificadas por classes do tipo edificadas de diferentes arranjos espaciais, diferentes condições de altura e adensamento dos elementos edificados, apresentam maior temperatura superficial; enquanto áreas com coberturas naturais, vegetadas ou de água, menores temperaturas. Verificaram também características específicas da condição espacial das ZCLs sobre os diferentes instantes diurnos e noturnos das imagens, como amplitudes maiores de Ts entre superfícies edificadas e não edificadas a noite, do que no período da manhã. Estas configurações são semelhantes a condição da variabilidade da temperatura do ar intraurbana, também reconhecida com o uso de ZCLs em outros casos (CARDOSO \& AMORIM, 2018; FENNER et al., 2017; SKARBIT et al., 2017).

Estudos que se utilizaram de outros produtos de Ts, com maior disponibilidade temporal, em conjunto com ZCLs em ambientes urbanos, como os do tipo MODIS, realizaram uma análise da variação sazonal das condições de temperatura (FERREIRA, 2019; FERREIRA \& DUARTE, 2018; GELETIČ et al., 2019; HU et al., 2019; MUSHORE et al., 2019; PONGRÁCZ et al., 2018; QUAN, 2019). A baixa disponibilidade temporal do produto ASTER, entretanto, é um desafio para análises como estas, principalmente se o clima da localidade favorecer a presença ou formação de nebulosidade durante todo o ano.

Para a região do Centro-Oeste brasileiro, no interior da América do Sul, a cidade de Cuiabá tem característica de um clima tropical com inverno seco, que garante uma baixa presença de nebulosidade ao longo do ano, principalmente nos meses de inverno. O uso da Ts do tipo ASTER em conjunto com a classificação de ZCLs pode dar maior detalhe escalar a análises de clima urbano, e na investigação de suas possíveis variabilidades espaciais e temporais, 
auxiliando no entendimento da manifestação deste fenômeno. A relação espacial entre estas variáveis também pode auxiliar na compreensão do efeito da morfologia urbana em seu clima local. Neste sentido, o presente artigo teve como objetivo analisar a variabilidade espacial e temporal da Ts de imagens ASTER considerando como unidades espaciais o contraste intraurbano de ZCLs da cidade de Cuiabá, Brasil.

\section{MATERIAL E MÉTODOS}

\section{1 ÁREA DE ESTUDO, SEU CLIMA E ZONAS CLIMÁTICAS LOCAIS}

Cuiabá é a capital do Estado brasileiro de Mato Grosso. A cidade localizase aproximadamente no par de coordenadas $15^{\circ} 36^{\prime} \mathrm{S}, 56^{\circ} 06^{\prime} \mathrm{W}$, inserida na zona climática tropical do hemisfério sul do planeta, e no interior do continente Sul-americano. A cidade possui altitudes médias de 140 a 260 metros, de um relevo de depressão dissecado, com morros, morrotes e planícies fluviais. E está inserida no bioma savânico do cerrado brasileiro (CUIABÁ, 2012). A Figura 1 traz a localização da cidade de Cuiabá e aspectos visíveis de sua mancha urbana.
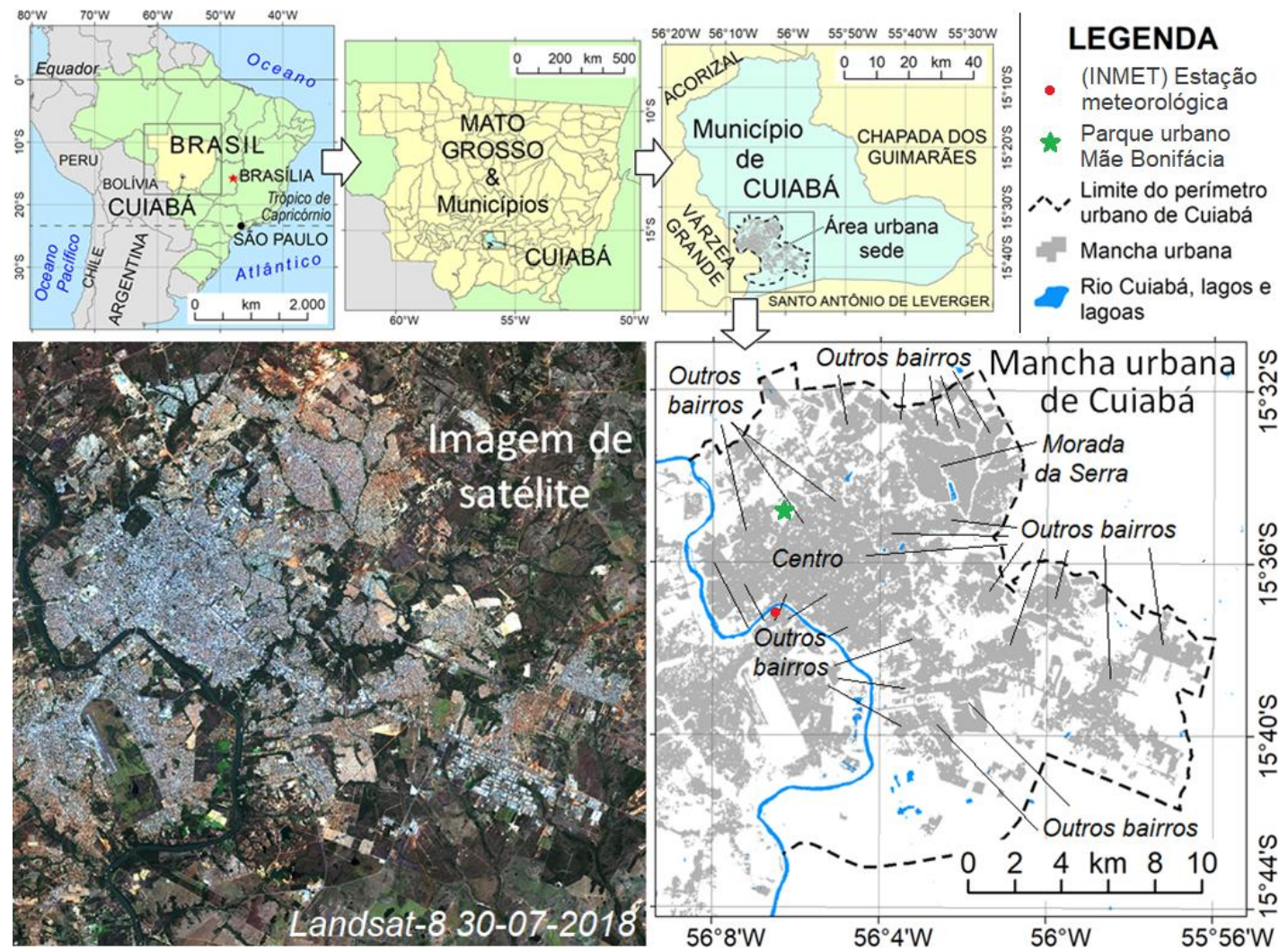

Figura 1 - Localização da cidade de Cuiabá e aspectos de sua mancha urbana.

A mancha urbana de Cuiabá localiza-se no interior do perímetro urbano sede do município. Sua área é de aproximadamente $165 \mathrm{~km}^{2}$, e ocupa cerca de $60 \%$ da área do perímetro urbano. A cidade é formada por 115 bairros e possui uma população de aproximadamente 600 mil habitantes (IBGE, 2018). A cidade foi fundada na localização da região do seu centro, no início do século XVIII, e 
se expandiu deste horizontalmente em todas as direções, atingindo a configuração espacial atual da mancha urbana (com referência ao ano 2017). O Rio Cuiabá, que dá nome a cidade, é o limite natural a oeste da área urbana e do município. Os demais limites do perímetro urbano aqui utilizados foram definidos pela Lei municipal no 4.719, de dezembro de 2004 (CUIABÁ, 2012). O entorno da mancha urbana de Cuiabá é formado por áreas de manejo rural, principalmente pastagem, e formações vegetadas do cerrado sob distintas condições: remanescentes, degradadas ou em recuperação. Em razão da escala, na Figura 1, não se representou outros cursos d'água do perímetro urbano além do Rio Cuiabá. Mas há uma rica hidrografia de outros rios e córregos que banham a cidade, que pode ser observada minimamente na imagem de satélite na mesma figura.

A região de Cuiabá apresenta um clima tropical com inverno seco, que condiciona duas estações climáticas anuais bem definidas: uma chuvosa e outra seca (MAITELLI, 1994; TARIFA, 2011), intercaladas por períodos de transição. A estação chuvosa ocorre geralmente entre os meses de outubro a março (primavera e verão), e a seca aproximadamente entre maio a setembro (outono e inverno). A precipitação nos meses do período seco é escassa, não sendo incomum não haver precipitação pluvial durante meses inteiros. O total médio anual de precipitação para Cuiabá varia entre 1.400 e $1.600 \mathrm{~mm}$ (TARIFA, 2011). Na estação chuvosa, as médias mensais da temperatura do ar são elevadas, e sua amplitude ao longo dos meses da estação é baixa. Na estação seca, há uma maior amplitude da temperatura do ar média mensal entre os meses que a compõem, sendo geralmente tanto os meses mais frios quanto os mais quentes de todo o ano (Figura 2). Isto se dá ao passo que a estação seca avança em seus meses, condicionando uma baixa disponibilidade hídrica na região.
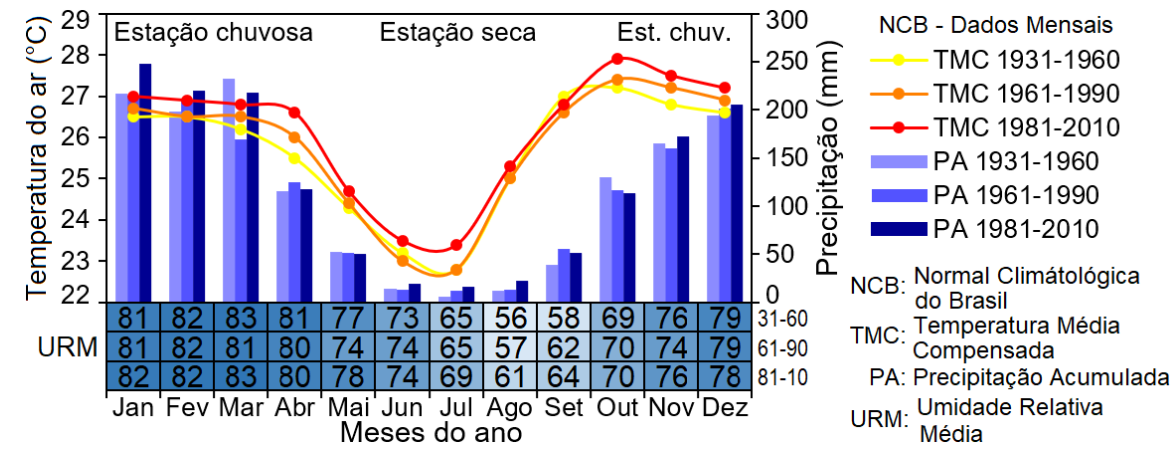

Figura 2 - Dados mensais de temperatura, umidade e precipitação de Cuiabá. Fonte: Instituto Nacional de Meteorologia (INMET; disponível em: inmet.gov.br).

As características dos períodos chuvoso e seco da região de Cuiabá são provenientes da circulação geral da atmosfera no contexto do continente Sulamericano (CAVALCANTI et al., 2009; TARIFA, 2011). Durante a estação chuvosa, a umidade da Massa de ar Equatorial continental chega até a região advinda do norte do Brasil, da região amazônica, através da atuação dos Jatos de Baixos Níveis que perpassam pelo interior do continente. A trajetória destes é influenciada pela atuação da Alta da Bolívia também no interior do continente. As condições do tempo quente e úmido favorecem a formação de sistemas de chuvas convectivas na região. Na estação seca, a incursão destes ares úmidos é reduzida em razão do deslocamento sobre o continente do Anticiclone Semifixo 
do Atlântico Sul, ou Alta Tropical do Atlântico Sul, que avança em baixos níveis, promovendo a subsidência do ar na região, inibindo a formação de chuva, caracterizando a Massa de ar Tropical continental, quente e seca. Entretanto, durante este período, eventuais incursões de Massas de ar Polares advindas do sul do continente, em razão do deslocamento do Anticiclone Migratório Polar, provocam o surgimento de zonas de instabilidade atmosféricas (frentes) no interior do continente, provocadoras de tempos instáveis, baixas temperaturas, aumento de umidade, entre outros fenômenos (MAITELLI, 1994; MENDONÇA \& DANNI-OLIVEIRA, 2007). Portanto, na escala regional, se verifica a variabilidade sazonal do clima que ocorre em Cuiabá. Esta variabilidade, na escala de detalhe local da cidade e de seu entorno rural, irá afetar também a condição de seu clima urbano.

O conjunto de elementos da superfície intraurbanos de Cuiabá, artificiais ou naturais, foram mapeados em Zonas Climáticas Locais (ZCL). Das 17 classes padrão de ZCLs, identificou-se comparavelmente em Cuiabá todas as classes, com exceção da ZCL 1, de edificações de elevada altura (prédios de mais de dez pisos; > $25 \mathrm{~m}$ ) e elevado adensamento. A mais atual configuração de ZCLs para Cuiabá mapeada, aqui utilizada, representativa do ano 2017 (FERREIRA, 2019), guarda semelhante característica com as condições da mancha urbana já na década de 2000. Destaca-se que, de modo geral, apenas bairros e regiões dos limites periféricos edificados da cidade apresentavam características distintas. $\mathrm{Na}$ região do centro de Cuiabá identifica-se ZCLs do tipo 2 e 3, o que mostra elevado adensamento edificado (Figura 3). Áreas mais verticalizadas, de ZCL 4, encontram-se mais isoladas e afastadas da região do centro de Cuiabá. Nos limites da mancha urbana da cidade, se verifica superfícies com características rurais, áreas arborizadas ou de outros tipos de vegetação com diferentes densidades espaciais. A partir destas ZCLs mapeadas, relacionou-se sua condição espacial por uma sobreposição simples, em conjunto com os dados em raster da temperatura da superfície (Ts) analisados. Também se derivou e pontuou áreas amostrais de ZCLs, que serão descritas mais à frente.
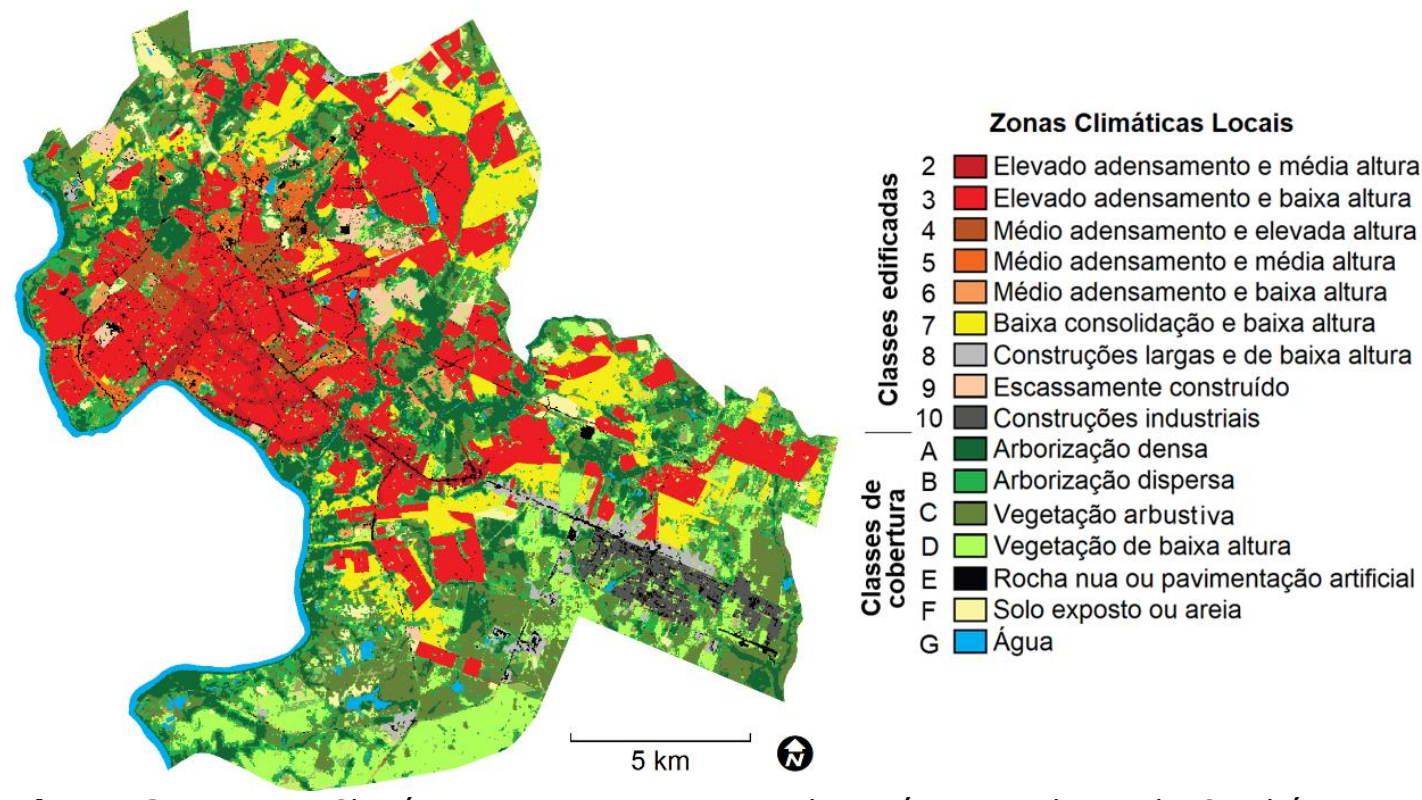

Figura 3 - Zonas Climáticas Locais no interior do perímetro urbano de Cuiabá. Fonte: FERREIRA, 2019. 


\subsection{PRODUTO ASTER E METODOLOGIAS DE ANÁLISE}

Foi utilizado o produto de sensoriamento remoto termal satelital AST08 (ABRAMS et al., 2002; EOSDIS/NASA, 2001), do sensor ASTER. Este produto é disponibilizado já para uso final, com valores de temperatura da superfície (Ts) estimados nos rasters instantâneos das cenas imageadas do ASTER. Os datasets do produto foram obtidos no banco de dados Earthdata, do EOSDIS/NASA (Earth Observing System Data and Information System/National Aeronautics and Space Administration). É necessário um cadastro gratuito para acesso. Em seu sistema de busca, entra-se com a informação do tipo de produto desejado, o intervalo de tempo da busca, e o recorte espacial da área de estudo. Depois, seleciona-se individualmente ou todo o resultado da pesquisa para download. Os arquivos são disponibilizados por um FTP (File Transfer Protocol) criado para o acesso ao banco de dados. Os arquivos de cada dataset instantâneo do produto são disponibilizados no formato ZIP (arquivo compactado). Com os rasters da Ts em um ambiente SIG (Sistema de Informações Geográficas) digital, aplica-se um fator de escala de 0,1 para converter seu ND (Número Digital) integro para resultar na temperatura na escala Kelvin. Posteriormente, pode-se converter a Ts de Kelvin para graus Célsius, subtraindo 273,15 . Os rasters do produto AST08 já vem georreferenciados na projeção UTM, com fuso e hemisfério da localidade.

A Figura 4 ilustra a dimensão espacial de uma cena ASTER, comparada com a de outros produtos sinérgicos de sensoriamento remoto que também permitem a estimativa da Ts (banda 6 Landsat-7; produto MODIS MOD11A1). 0 imageamento do sensor ASTER é sinérgico ao do sensor MODIS/Terra, pois ambos se encontram a bordo do satélite Terra, e compartilham o mesmo campo de varredura, com diferença na largura da faixa de arraste e outras características.

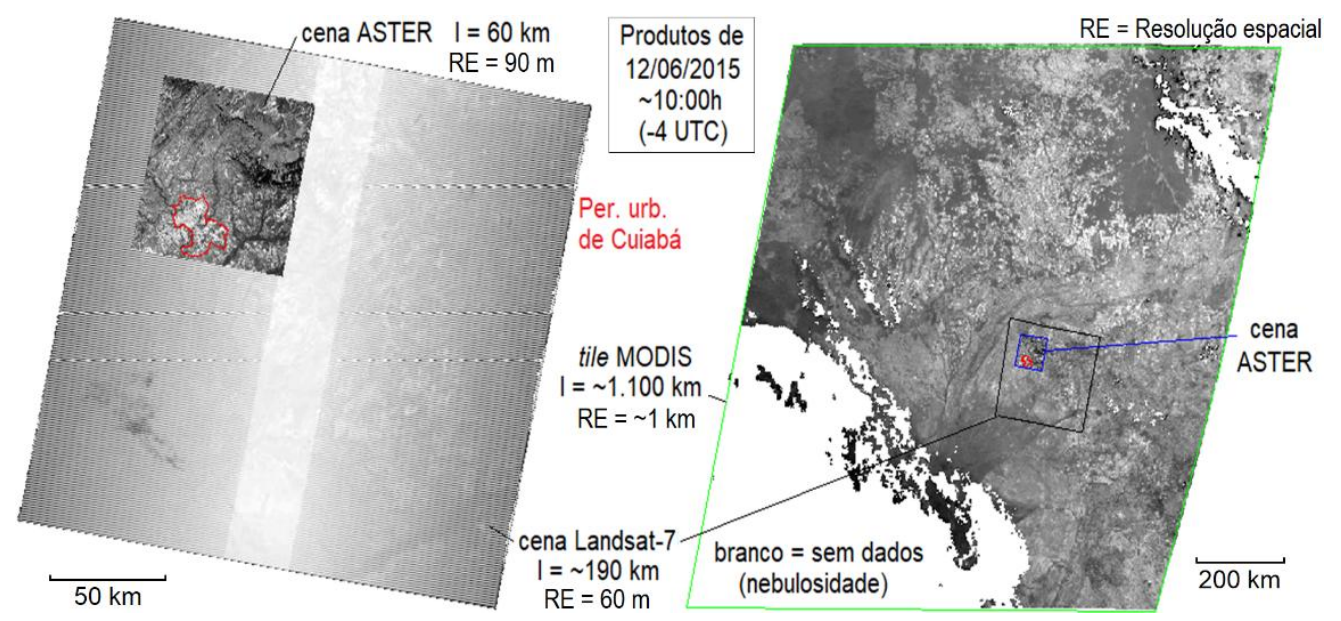

Figura 4 - Sobreposição de cenas sinérgicas ASTER, Landsat e MODIS.

Foram adquiridos pouco mais de 100 datasets ASTER instantâneos diários, datados dos anos 2000 até 2017. Se verificou destes, visualmente, apenas 29 em boas condições de uso, com ausência de nebulosidade e que imageiam parte da cidade de Cuiabá. Diferente do que se vê no exemplo da cena ASTER na Figura 4, a posição destas variam na superfície do planeta ao longo do ciclo de imageamento do sensor. Isto faz com que o imageamento de uma mesma superfície ocorra com um deslocamento longitudinal da cena, onde 
uma mesma área possa não ser imageada dentro do intervalo de 16 dias do ciclo. Por exemplo, muitas cenas não imageiam a cidade de Cuiabá inteira (Figura 8) em função desta variação da posição do campo de varredura do ASTER em órbita em relação a superfície. Destaca-se que com isto, também, o ângulo de visada do ASTER em relação a uma mesma superfície oblíqua imageada torna-se variável. Isto provoca uma variabilidade na magnitude do sinal de radiação, e posteriormente na Ts, em razão do ângulo distinto que se aparentará as condições da superfície imageada. Mas em função da generalização do sinal da superfície pela resolução espacial resultante do sensor, tal erro se mostra pouco anunciado, visto que se analisa padrões de ordem espaciais de dimensões maiores, na resolução espacial dos pixels $(90 \mathrm{~m})$. Em alvos urbanos, destaca-se a mistura do sinal de radiação de superfícies verticais e horizontais da cidade, que já caracterizam uma generalização no sinal. Para tanto, aqui, faz-se uma análise de condições gerais dos níveis da Ts dos pixels, com médias e distribuições por padrões de áreas delimitadas da superfície, representativas dos elementos contidos em ZCLs.

A Figura 5 mostra a distribuição temporal das imagens instantâneas do produto ASTER obtidas. De um total de 29 imagens, 22 são diurnas, do horário da manhã, imageadas aproximadamente as 10:00 horas do horário local de Cuiabá (-4 UTC), e 7 noturnas, imageadas aproximadamente as 22:00h.

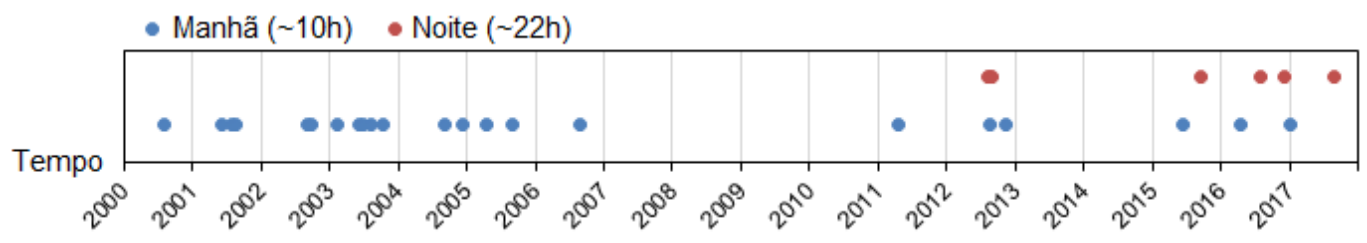

Figura 5 - Disponibilidade temporal das imagens AST08 obtidas para Cuiabá.

Embora a série temporal de imagens seja fragmentada ao longo dos anos (Figura 5), está foi suficiente para verificar condições de variação sazonal e horária da Ts. Na análise destes processos, são realizadas comparações visuais de imagens de instantes temporais distintos e similares, sazonal e horários. São também amostrados e analisados perfis da Ts sobre estas imagens. E se analisa a Ts sobre Zonas Climáticas Locais (ZCL) amostrais definidas (Figura 6).

A Figura 6 ilustra as áreas ou zonas amostrais selecionadas, representativas das ZCLs identificadas em Cuiabá, bem como representações visuais de algumas destas. Destaca-se que para as classes ZCL B, C e D, se selecionou áreas amostrais com misturas destas, criando uma classe provisória 'BCD'. Recomenda-se, porém, o uso das classes isoladas para melhor precisão na análise espacial. A partir destas áreas amostrais de ZCLs foram estimados valores médios da Ts ASTER dos pixels contidos em seu interior, e estes dados foram analisados em sua variabilidade e distribuição espaço-temporal. As áreas amostradas superam uma área maior que $70 \mathrm{mil} \mathrm{m}^{2}$, superior à dos pixels individuais ASTER de 90x90m $\left(8.100 \mathrm{~m}^{2}\right)$. 


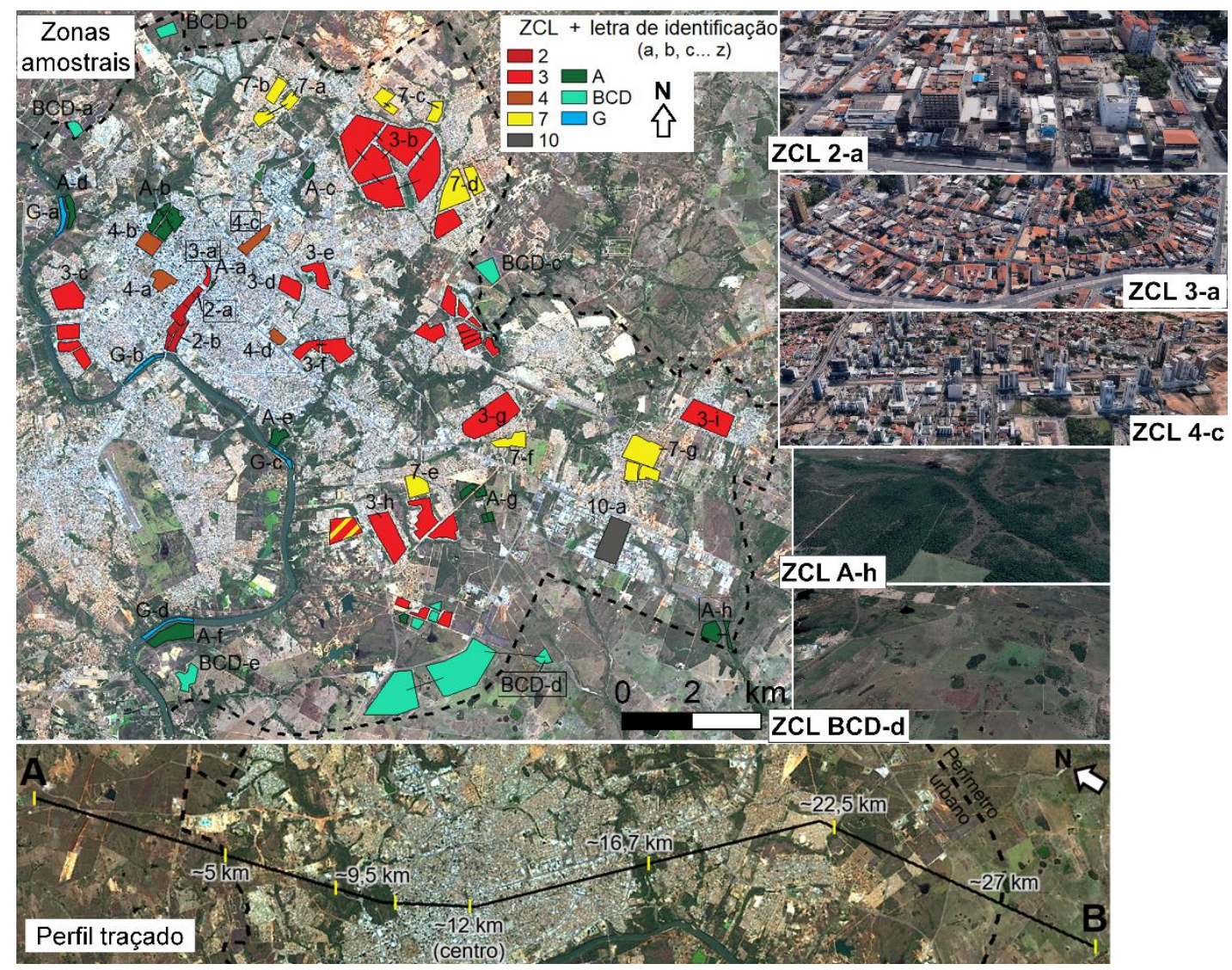

Figura 6 - ZCLs amostrais e perfil para análise da Ts.

A Figura 6 traz também a representação do perfil espacial traçado. Ele foi utilizado para verificar a variabilidade espacial e temporal da Ts de superfícies representativas do ambiente urbano e rural do entorno de Cuiabá. O comprimento do perfil de $30 \mathrm{~km}$ perpassa por áreas rurais a norte e sul da cidade, bem como atravessa condições de arranjos dos elementos do espaço urbano distintos, classificados por meio das ZCLs descritas nas Figuras 3, 6, 9 e 10.

\section{RESULTADOS E DISCUSSÃO}

Aspecto comum observado nos produtos de temperatura da superfície (Ts) é o da relação da intensidade dos níveis de temperatura, ou magnitude, com os tipos de superfícies imageados. Áreas edificadas, de água, vegetação, de diferente formas e estruturas de organização na superfície, imprimirão características e magnitudes específicas em cada imagem. Aliando-se isto com a disponibilidade de instantes noturnos do produto ASTER, verifica-se um aprimoramento temporal na análise de condições da Ts de áreas urbanas. A Figura 7 traz um exemplo comparativo de imagens ASTER da Ts que mostram Cuiabá numa mesma condição sazonal e de tempo atmosférico (estação seca com céu sem nebulosidade, e sem chuva em dias anteriores), mas em horários distintos. 



Figura 7 - Comparação da Ts entre instantes diurno e noturno.

$\mathrm{Na}$ Figura 7, na imagem da manhã, observa-se que tanto áreas edificadas quanto áreas do entorno da cidade, de pastagem e vegetação dispersa, apresentam similares níveis de Ts. O que se diferencia destas, com temperaturas mais amenas, são áreas associadas a arborização densa e corpos d'água, como rios, lagos e lagoas em Cuiabá e em seu entorno próximo. Com certo detalhe, na área urbana, no período da manhã, pode ser identificado a área edificada do centro de Cuiabá e seu entorno, que possui um padrão espacial da Ts distintivo, que manifesta sua forma característica em muitas das outras imagens. O bairro Morada da Serra, a nordeste na área urbana, produz efeito similar, e se mostra mais aquecido. Este bairro possui uma superfície relativamente homogênea de casas térreas com alta densidade edificada, de um tipo arquitetônico de conjunto habitacional, e abrange uma área de cerca de 7 $\mathrm{km}^{2}$.

Na imagem noturna da Figura 7, verifica-se um maior contraste da Ts entre o ambiente edificado da cidade e o rural do entorno do perímetro urbano. As áreas edificadas se mostram mais aquecidas que as áreas vegetadas, para mais de $10^{\circ} \mathrm{C}$. As áreas de corpos d'água mostram uma maior inércia térmica, variando pouco sua temperatura entre ambos os períodos horários. Observa-se nas áreas vegetadas um gradiente de temperatura, sendo as mais próximas de cursos d'água mais amenas que as de campinas, pastos e matas secas no entorno e com proximidade das áreas urbanizadas.

A Figura 8 traz instantes noturnos da Ts em Cuiabá, de imagens de diferentes datas no período seco. Embora havendo diferenças na intensidade da Ts entre as imagens de diferentes datas na Figura 8, o padrão espacial da Ts é similar em cada uma. Se observa na região do centro de Cuiabá, em função desta formar uma grande área continuamente edificada, que a Ts atinge níveis ainda maiores. Isto se associa ao contexto do arranjo espacial dos elementos urbanos desta área. É na região do centro e seu entorno que se concentram áreas edificadas de densidade alta e de alta a baixa altura. Em razão destas formarem cânions urbanos, isto favorece a absorção de energia solar pelas superfícies verticais durante o dia, e um mais prolongado tempo de dissipação 
deste calor durante a noite, em função do aprisionamento provocado pelos cânions (OKE et al., 2017). A área do centro no período noturno é mais aquecida que outras áreas edificadas periféricas da cidade, que se amenizam no limite com o ambiente rural.

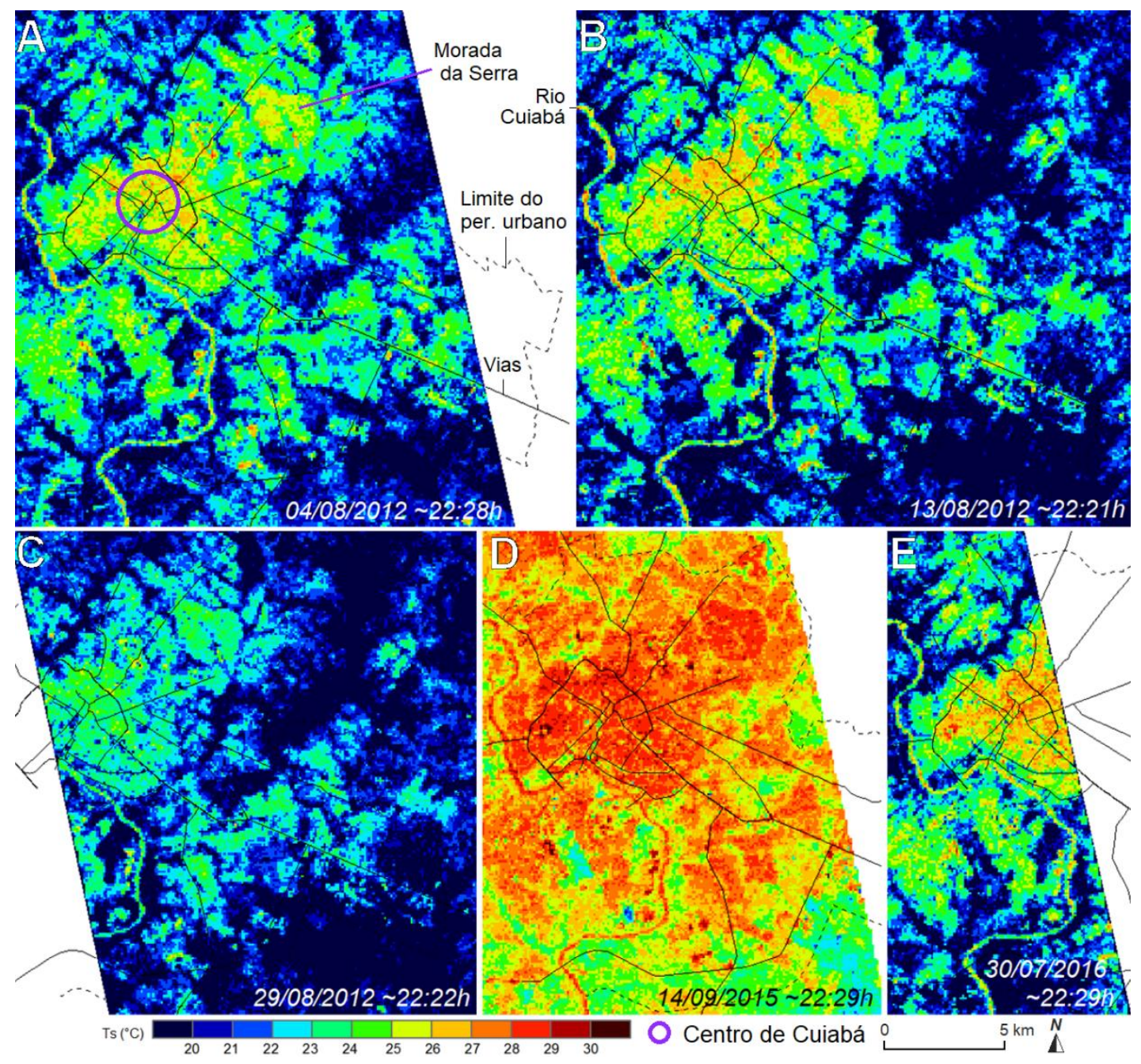

Figura 8 - Imagens da Ts em instantes noturnos do período seco.

Diferente do centro e do bairro Morada da Serra, bairros periféricos a estas regiões, a leste, sudeste e sul, e a noroeste na cidade, apresentam níveis mais inferiores da Ts. Estes bairros possuem em seus entornos áreas de cursos d'água arborizados, ou áreas de outros tipos de vegetação, mas que não são ocupadas por edificações. Isto auxilia na dissipação do calor noturno, uma vez que se cria uma circulação atmosférica local de uma área mais aquecida para uma mais amena. Diferente do que ocorre no centro, por ter um entorno horizontal edificado que se distribui numa área maior.

Outra forma de análise e representação da Ts intraurbana se verifica nos gráficos de perfis horizontais que ilustram as Figuras 9 e 10. Estes mostram a variabilidade da Ts diretamente extraída de imagens sob diferentes temporalidades, em instantes matutinos e noturnos, nos períodos climáticos chuvoso e seco. As Figuras 9 e 10 pontuam também a condição da Ts média 
para trechos representativos do perfil, a indicação das Zonas Climáticas Locais (ZCL) ali localizadas, e distinções urbano/rural genéricas.



Figura 9 - Dados de perfis da Ts em Cuiabá no período chuvoso.

Na Figura 9, no período da manhã da estação chuvosa, se observa um grande contraste entre a Ts das áreas edificadas com a das áreas rurais ou vegetadas, de mais de $10^{\circ} \mathrm{C}$. Temperaturas mais amenas podem ser observadas na área do Parque Mãe Bonifácia, uma ZCL A. A maior disponibilidade de água na superfície no tempo chuvoso faz com que as áreas mais densamente arborizadas e mais umidificadas absorvam mais radiação sem elevarem muito sua temperatura, em função da alta inércia térmica da água e destas superfícies. Já superfícies edificadas, que são impermeáveis, e contam com específicas materialidades e arranjos estruturais, prontamente se aquecem com a radiação solar que as atingem. Este é o caso da área urbana predominante construída entre os quilômetros 10 e 16. Nesta, se verificam áreas mais aquecidas que outras, em função da materialidade urbana distinta, mais continuamente edificada, diferente das do km 16 ao 22, que é perpassada por matas ciliares de rios e córregos, provocando uma descontinuidade nos níveis da Ts, que diminuem a média do trecho (barra vermelha). No período noturno chuvoso, a Ts da cidade e a do ambiente rural apresentam um baixo gradiente entre si, em função do resfriamento mais intenso das áreas urbanas pelo ar úmido e ameno que predomina nesta época do ano, e do fato das áreas rurais apresentarem uma menor amplitude diária de variação da Ts.

Na Figura 10, do período seco (mesmas imagens da Figura 7), verifica-se padrões espaciais aproximadamente inversos aos da Figura 9, tanto na condição espacial diurna e noturna da Ts, quanto na amplitude entre os diferentes tipos de superfície. A amplitude horária da Ts das áreas rurais (manhã x noite), que no tempo chuvoso se observa ser baixa, o é em relação a amplitude do período seco, que ao contrário, é elevada. No período da manhã, durante a estação seca, tanto as áreas urbanas quanto o ambiente rural apresentam elevada Ts, mostrando um baixo gradiente entre si. No período noturno da estação seca, no ambiente rural, em função de propriedades aerodinâmicas, radiativas, térmicas e de umidade da superfície, este perde energia com mais facilidade que o ambiente urbano, se mostrando menos aquecido. O ambiente urbano, ao contrário, estoca mais energia em seu interior, e a dissipa com menor 
intensidade a noite, favorecendo-o a permanecer mais aquecido. Esta condição possibilita a intensificação de ilhas de calor atmosféricas em noites de céu claro e tempo calmo no período seco. Em Cuiabá, tais características já foram observadas em trabalhos como os de Maitelli (1994), Pinho (2008), Santos (2013), e Teobaldo Neto (2019), e comparadas com a condição da Ts de diferentes outros tipos de produtos, Landsat, MODIS e GOES (FERREIRA, 2019).

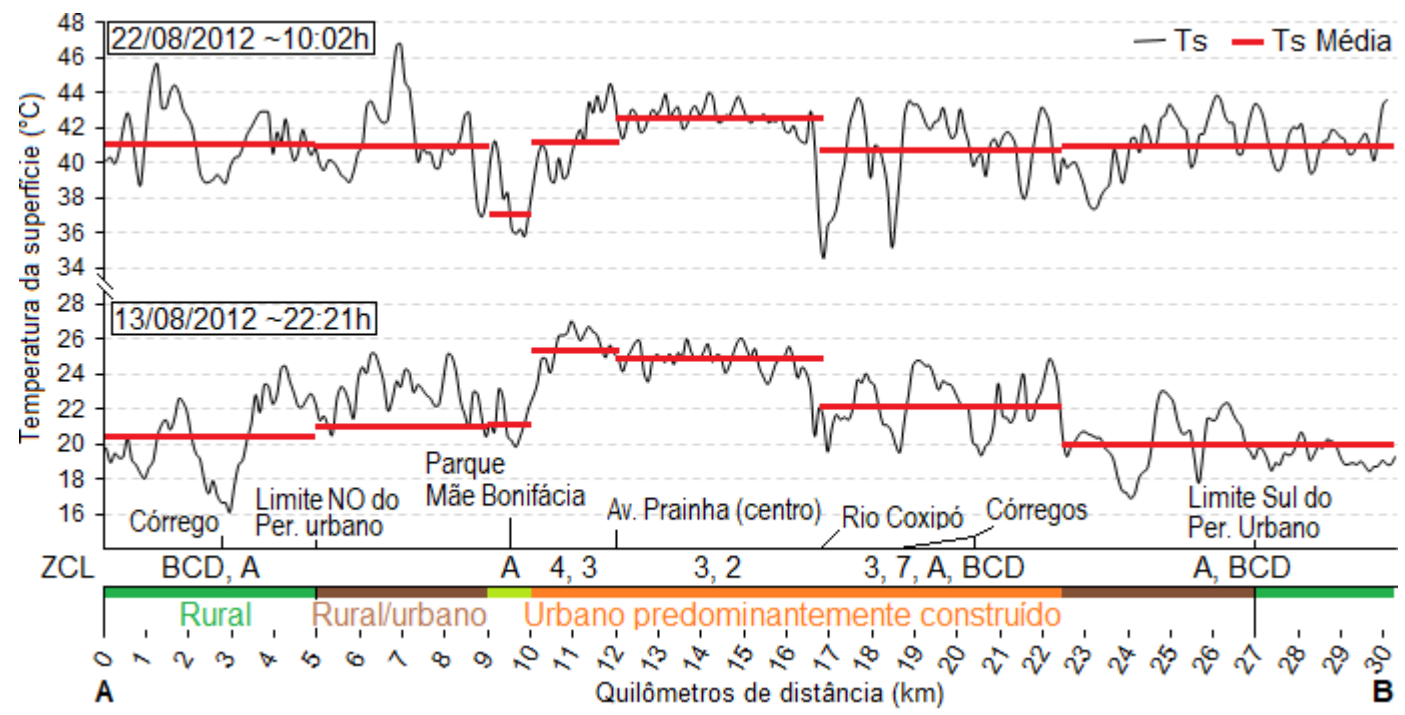

Figura 10 - Dados de perfis da Ts ASTER em Cuiabá no período seco.

A relação da Ts entre os diversos tipos de superfície urbanas e de seu entorno é analisada por condições de sua magnitude e amplitude. Esta relação irá variar conforme as horas do dia e sazonalmente. Na Figura 11, comparou-se o nível da Ts de amostras de ZCLs em diferentes datas, ordenadas numa escala temporal mensal, a fim de se verificar tanto a variabilidade sazonal quanto a variação horária da Ts sob diferentes ZCLs da cidade de Cuiabá e seu entorno.

Na Figura 11, os dados do período diurno de diferentes tipos de ZCLs, edificadas e vegetadas, mostram uma maior amplitude da Ts nos meses do período chuvoso $\left(>10^{\circ} \mathrm{C}\right)$. No período seco, de manhã, esta amplitude é menor, se comparado com a anterior $\left(<10^{\circ} \mathrm{C}\right)$, e ainda ocorre uma intensificação da Ts sobre as áreas vegetadas no final do período seco, em função do estresse hídrico prolongado que avança com a escassez de chuvas na região. No período noturno, as áreas edificadas se encontram predominantemente mais aquecidas que as vegetadas. Isto implica diretamente na configuração do clima urbano de uma cidade, visto que isto afetará a também a condição termodinâmica da atmosfera urbana. A ZCL 4, de elevada altura e médio adensamento, mesmo não sendo de alto adensamento, como uma ZCL 1 , se sobressai com níveis de Ts maiores que outras áreas edificadas de adensamento maior (ZCLs 2 e 3). Se verifica que não só o adensamento edificado implica nas condições da Ts, mas também outras características morfológicas estruturais e tipológicas, como a altura dos elementos e sua materialidade, visto as áreas edificadas de alta elevação serem compostas por edifícios cujas superfícies verticais de concreto mantêm um maior armazenamento de calor noturno que a superfície de asfalto de ruas, ou coberturas de telhados das edificações de altura inferior, em comparação. 


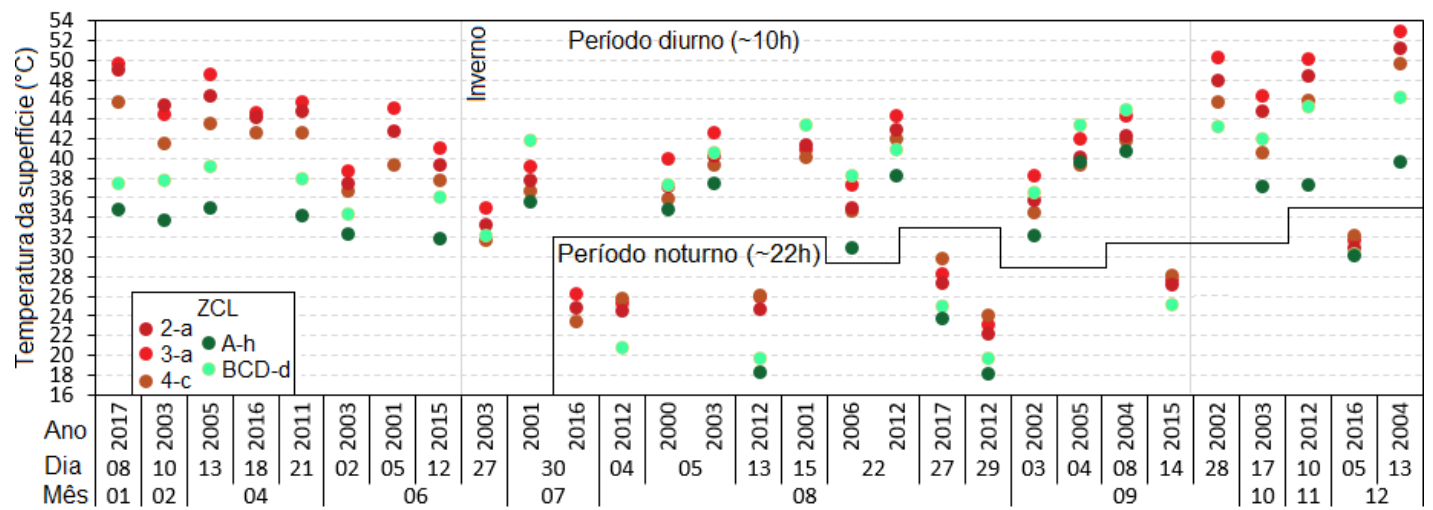

Figura 11 - Variabilidade sazonal e horária em dados diários da Ts de ZCLs.

A variabilidade sazonal observada na Figura 11, entre os dados amostrais, é representativa da condição climática da região de Cuiabá. Durante os meses do verão, observa-se elevadas temperaturas variando numa menor amplitude durante a estação; e no inverno, temperaturas tanto mais amenas quanto quentes, numa amplitude intrassazonal variável e maior. A variabilidade da Ts ao longo do ano segue um padrão semelhante ao da temperatura do ar em superfície, vista por dados meteorológicos (Figura 2). Na Figura 12, observase uma relação análoga quanto a diferenciação dos níveis da Ts entre classes de ZCLs distintas em função da condição sazonal do clima e das horas do dia.

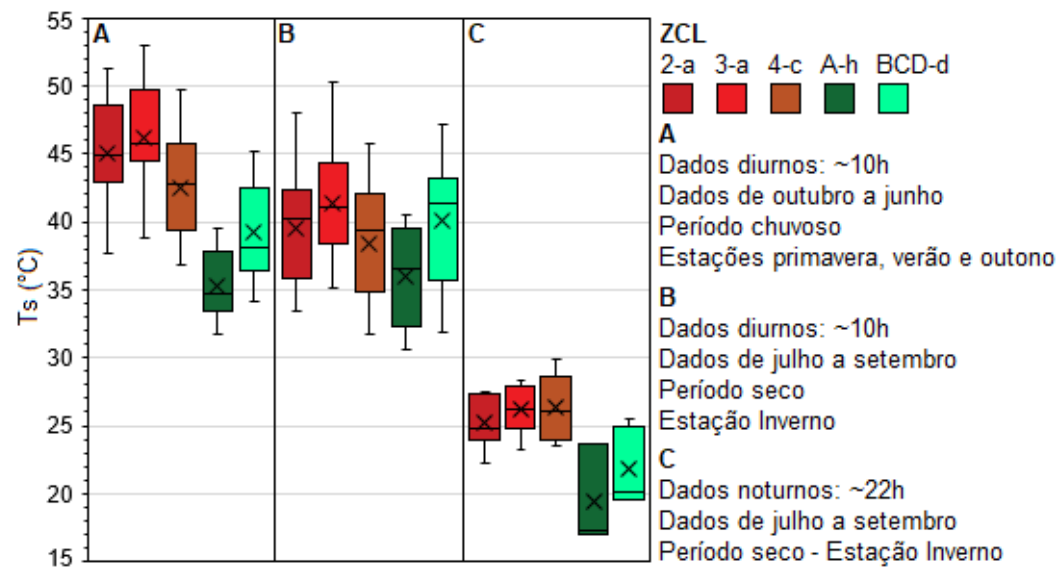

Figura 12 - Distribuição da variabilidade temporal da Ts em ZCLs selecionadas.

Na Figura 12, a Ts na área da classe ZCL 2, de média altura e elevado adensamento edificado, apresenta uma variação sazonal no período matutino de cerca de $5^{\circ} \mathrm{C}$, valor comum também nos outros tipos de áreas edificadas, com temperaturas mais elevadas no período chuvoso que no seco. No período noturno, sua Ts entre as áreas edificadas, principalmente em comparação a ZCL 3, apresenta-se mais amena. A Ts na classe ZCL 3, de baixa altura e elevado adensamento edificado, durante o período noturno, apresenta-se elevada, pouco menos que a ZCL 4. A região do centro histórico de Cuiabá, que esta classe representa ( $Z C L$ 3-a), se mostra como uma das áreas edificadas mais aquecidas da cidade, em diferentes condições sazonais e horas do dia. Esta área é favorável a ser o pico de ilhas de calor atmosféricas, por sua localização na cidade. A Ts na ZCL 4, de elevada altura e adensamento médio, apresenta baixa intensidade durante 0 horário diurno, provavelmente favorecida pelo 
sombreamento dos edifícios mais verticalizados. Entretanto, à noite, esta é uma área edificada que permanece mais aquecida, em razão do efeito das superfícies verticais dos edifícios perderem calor para o ar mais lentamente.

A Ts da ZCL A, na Figura 12, de arborização densa, representa a condição do topo do dossel das árvores. Durante o horário diurno, esta superfície se mostra menos aquecida em ambas estações sazonais, com uma amplitude maior na estação seca do que na chuvosa. Esta ZCL apresenta menor Ts à noite, superando a ZLC BCD. A área de arborização dispersa e de vegetação de baixa altura (ZCL BCD) apresenta baixa Ts assim como a área de arborização densa, em comparação com as áreas edificadas. Entretanto, durante o período diurno da estação de inverno (seco), esta área apresenta níveis da Ts que podem superar os das áreas edificadas. No período diurno da estação chuvosa, com o solo úmido, a Ts da ZCL BCD torna-se mais amena, ao passo que sua vegetação também se encontra mais vigorosa. Neste período, esta área se encontra ainda predominantemente mais aquecida que a área da classe $Z C L$ A. Esta característica de maior amplitude da Ts da ZCL BCD apontada, se associa com uma quantidade maior de áreas de solo exposto ou superfícies secas, não associadas a corpos d'água, em meio a área. Esta é uma característica das formações vegetadas do cerrado, ao qual esta classe representa no entorno rural de Cuiabá. Sua variabilidade sazonal é sensível a mudanças no conteúdo de umidade que ocorrem na localidade de Cuiabá, de um clima tropical com inverno seco.

\section{CONCLUSÕES}

Se verificou que em instantes diurnos (da manhã) do período sazonal chuvoso, a temperatura da superfície (Ts) entre o ambiente urbano e intraurbano da cidade de Cuiabá e seu entorno rural apresenta elevada amplitude positiva, sendo o urbano mais aquecido que o rural. Já em instantes noturnos deste mesmo período sazonal, esta amplitude é menor. Em instantes diurnos durante o período sazonal de escassez de chuvas (seco), a Ts entre o ambiente urbano e intraurbano e o entorno rural apresenta reduzida amplitude positiva. Sendo o primeiro ainda mais aquecido que o segundo, porém este segundo se mostra mais aquecido em função da escassez de umidade no sistema superfície-atmosfera da região nesta época do ano. Já em instantes noturnos deste período seco, esta amplitude é maior em função das propriedades da superfície dos ambientes analisados.

A Ts do produto ASTER analisada, apresenta uma variabilidade espacial e em magnitude paralela entre os padrões espaciais das Zonas Climáticas Locais (ZCL) de Cuiabá. As características das diferentes ZCLs, reconhecidamente relacionadas a variabilidade espacial atmosférica do clima urbano (STEWART, 2011; STEWART \& OKE, 2012), também guardam relação sobre as condições da Ts do ambiente. Isto atesta a condição de inter-relacionamento entre superfície e atmosfera, principalmente quanto suas condições de temperatura manifestadas espacialmente em diferentes graus de magnitude.

Em Cuiabá, verifica-se que a região do centro da cidade, de elevado adensamento edificado (ZCLs 2, 3), apresenta-se como a área de Ts mais aquecida da mancha urbana, em detrimento de áreas rurais e urbanas periféricas. Entretanto, estas últimas também mostram Ts elevada, por 
concentrarem áreas edificadas densamente edificadas ( $Z C L$ 3, principalmente), mas em espaços reduzidos, contornados por áreas vegetadas de Ts mais amenas (ZCLs A ou BCD). Áreas com verticalização de média densidade ( $Z C L$ 4), apresentaram elevada Ts no período noturno, superiores as de ZCLs 2 e 3. Os padrões espaço-temporais da Ts de Cuiabá podem influenciar diretamente a condição da temperatura do ar em sua camada atmosférica do dossel urbano, produzindo padrões espaciais intraurbanos distintos, definindo características de seu clima urbano.

\section{REFERÊNCIAS}

ABRAMS, M.; HOOK, S.; RAMACHANDRAN, B. ASTER User Handbook. Jet Propulsion Laboratory, EROS Data Center, ver. 2, 2002.

CARDOSO, R. S.; AMORIM, M. C. C. T. Urban heat island analysis using the 'local climate zone' scheme in Presidente Prudente, Brazil. Em: Investigaciones Geográficas, n. 69, 2018.

CAVALCANTI, I. F. A.; FERREIRA, N. J.; SILVA, M. G. A. J.; DIAS, M. A. F. (orgs.). Tempo e Clima no Brasil. São Paulo: Oficina de Textos, 2009.

CUIABÁ (Prefeitura Municipal). Perfil socioeconômico de Cuiabá. Secretaria Municipal de Desenvolvimento Urbano - SMDU; Diretoria de Urbanismo e Pesquisa - DUP. Cuiabá-MT: Central de Texto, v. V, 2012.

EOSDIS/NASA (Earth Observing System Data and Information System/National Aeronautics and Space Administration). Produto ASTER Level 2 Surface kinetic temperature, AST08 V003. NASA/METI/AIST/Japan Spacesystems, and U.S./Japan ASTER Science Team. Earthdata. 2001. Disponível em: https://search.earthdata.nasa.gov/search. Acesso em: julho de 2017.

FENNER, D.; MEIER, F.; BECHTEL, B.; OTTO, M.; SCHERER, D. Intra and inter 'local climate zone' variability of air temperature as observed by crowd sourced citizen weather stations in Berlin, Germany. Em: Meteorologische Zeitschrift, v. 26, n. 5, 2017.

FERREIRA, H. V. L. A organização do espaço urbano e a estrutura térmica da cidade de Cuiabá-MT. Dissertação (Mestrado em Geografia). UFMT, Cuiabá-MT, 2019.

FERREIRA, L. S.; DUARTE, D. H. S. Land surface temperature, vegetation cover and urban morphology over different local climate zones in São Paulo Metropolitan Region. Em: 10th International Conference on Urban Climate/14th Symposium on the Urban Environment, 2018.

GELETIČ, J.; LEHNERT, M.; DOBROVOLNÝ, P. Land Surface Temperature Differences within Local Climate Zones, Based on Two Central European Cities. Em: Remote Sensing, v. 8, ed. 10, 2016.

GELETIČ, J.; LEHNERT, M.; SAVIĆ, S.; MILOŠEVIĆ, D. Inter-/intra-zonal seasonal variability of the surface urban heat island based on local climate zones in three central European cities. Em: Building and Environment, v. 156, 2019.

HU, J.; YANG, Y.; PAN, X.; ZHU, Q.; ZHAN, W.; WANG, Y.; MA, W.; SU, W. Analysis of the Spatial and Temporal Variations of Land Surface Temperature Based on Local Climate Zones: A Case Study in Nanjing, China. Em: IEEE 
Journal of Selected Topics in Applied Earth Observations and Remote Sensing, v. 12, 2019.

IBGE (Instituto Brasileiro de Geografia e Estatística). IBGE Cidades - Cuiabá. Diretoria de Pesquisas, Coordenação de População e Indicadores Sociais, Estimativas da população residente com data de referência $1^{\circ}$ de julho de 2018 . 2018. Disponível em: https://cidades.ibge.gov.br/brasil/mt/cuiaba/panorama. Acesso em: junho de 2019.

MAITELLI, G. T. Um estudo tridimensional de Clima Urbano em cidades tropicais continentais: o exemplo de Cuiabá/MT. Tese (Doutorado em Geografia Física). USP, São Paulo-SP, 1994.

MENDONÇA, F.; DANNI-OLIVEIRA, I. M. Climatologia - noções básicas e climas do Brasil. São Paulo-SP: Oficina de Textos, 2007.

MUSHORE, T. D.; DUBE, T.; MANJOWE, M.; GUMINDOGA, W.; CHEMURA, A.; ROUSTA, I.; ODINDI, J.; MUTANGA, O. Remotely sensed retrieval of Local Climate Zones and their linkages to land surface temperature in Harare metropolitan city, Zimbabwe. Em: Urban Climate, v. 27, 2019.

OKE, T. R.; MILLS, G.; CHRISTEN, A.; VOOGT, J. A. Urban Climates. Cambridge University Press, ed. 1, 2017.

PINHO, J. G. Uso do solo, ilha de calor e distribuição espacial das chuvas na cidade de Cuiabá - MT. Dissertação (Mestrado em Geografia). UFMT, Cuiabá-MT, 2008.

PONGRÁCZ, R.; BARTHOLY, J.; DIAN, C.; DEZSŐ, Z. Intra-annual Characteristics of the Relationship between the Surface Temperature-Based Urban Heat Island Intensity and the Local Climatic Zones. Em: American Meteorological Society 98th Annual Meeting, Austin, Texas, 2018.

QUAN, J. Multi-Temporal Effects of Urban Forms and Functions on Urban Heat Islands Based on Local Climate Zone Classification. Em: International Journal of Environmental Research and Public Health, v. 16, ed. 12, 2019.

SANTOS, F. M. M. Influência da ocupação do solo na variação termohigrométrica na cidade de Cuiabá-MT. Tese (Doutorado em Física Ambiental). UFMT, Cuiabá-MT, 2012.

SKARBIT, N.; STEWART, I. D.; UNGER, J.; GÁL, T. Employing an urban meteorological network to monitor air temperature conditions in the 'local climate zones' of Szeged, Hungary. Em: International Journal of Climatology, v. 37, 2017.

STEWART, I. D. Redefining the urban heat island. Tese (PhD em Geografia). University of British Columbia, Vancouver, Canadá, 2011.

STEWART, I. D.; OKE, T. R. Local Climate Zones for Urban Temperature Studies. Em: Bulletin of the American Meteorological Society, v. 93, n. 12, 2012.

STEWART, I. D.; OKE, T. R.; KRAYENHOFF, E. S. Evaluation of the 'local climate zone' scheme using temperature observations and model simulations. Em: International Journal of Climatology, v. 34, 2014.

TARIFA, J. R. Mato Grosso clima: análise e representação cartográfica. CuiabáMT: Entrelinhas, 2011. 
TEOBALDO NETO, A. A geografia do risco e da vulnerabilidade ao calor em espaços urbanos da zona tropical: o caso Cuiabá/MT. Tese (Doutorado em Geografia). UNESP, Presidente Prudente-SP, 2019.

WANG, C.; MIDDEL, A; MYINT, S. W.; KAPLAN, S.; BRAZEL, A. J.; LUKASCZYK, J. Assessing local climate zones in arid cities: The case of Phoenix, Arizona and Las Vegas, Nevada. Em: ISPRS Journal of Photogrammetry and Remote Sensing, v. 141, 2018.

ZHAO, C. Linking the Local Climate Zones and Land Surface Temperature to investigate the Surface Urban Heat Island, a case study of San Antonio, Texas, U.S. Em: ISPRS Annals of the Photogrammetry, Remote Sensing and Spatial Information Sciences, v. IV-3, 2018 